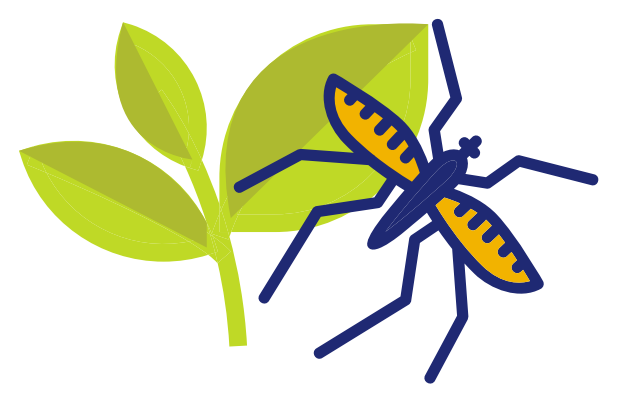

\title{
ENGENHARIA BIOMÉDICA COMO FERRAMENTA PARA O CONTROLE BIOLÓGICO DE ARBOVIROSES
}

\author{
BIOMEDICAL ENGINEERING AS A TOOL FOR THE BIOLOGICAL CONTROL \\ OF ARBOVIRUSES
}

\begin{abstract}
Joab de Souza Arouche
Fonoaudiólogo, Mestre em Ciência e Engenharia de Materiais - UFAM; Especialista em Saúde Coletiva com ênfase em Cirurgia de Cabeça e Pescoço - UCAM, Aperfeiçoamento em Atenção à Saúde das Pessoas privadas de liberdade - UFSC. Atualmente pesquisador na FAPEAM. E-mail: arouchejoab16@gmail.com
\end{abstract}

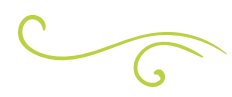

\section{RESUMO}

Esta pesquisa teve como objetivo confirmar por meio de testes larvicidas a eficácia do óleo essencial da Piper callosum contra larvas do mosquito Aedes aegypti. Os materiais e métodos aplicados foram essenciais para confirmar os resultados, o óleo essencial da Piper callosum fornecido pela EMBRAPA foi analisado no refratômetro ATAGO. A constituição química do material fornecido, foi determinada por Cromatografia Gasosa acoplada à Espectrometria de Massas (CG/EM) na Central Analítica/UFAM. Os dados foram confirmados com a literatura. A determinação dos grupos funcionais orgânicos do óleo essencial in natura foi analisada no espectrofotômetro de infravermelho por transformada de Fourier e o teste larvicida foi realizado no Laboratório de Malária e Dengue / LMD-CSAS (INPA). Os resultados aprontaram que o óleo essencial da Piper callosum se encontrava estável e que o safrol é seu maior constituinte. Dois estiramentos típicos de ligação dupla de anel aromático foram encontrados no
FTIR referentes aos componentes com maiores participações. As atividades larvicidas foram confirmadas em grandes concentrações nas primeiras $24 \mathrm{~h}$. O óleo essencial da Piper callosum é formado por várias substâncias com diversas propriedades bioativas, sendo uma alternativa promissora para o controle biológico de arboviroses.

Palavras-chave: Aedes aegypti. Arboviroses. Controle biológico. Piper callosum.

\section{ABSTRACT}

This research aimed to confirm through larvicidal tests the effectiveness of the essential oil of Piper callosum against larvae of the mosquito Aedes aegypti. The materials and methods applied were essential to confirm the results, the essential oil of Piper callosum supplied by EMBRAPA was analyzed in the ATAGO refractometer. The chemical constitution of the material supplied was determined by Gas Chromatography coupled to Mass 
Spectrometry (CG / EM) at the Analytical Center / UFAM. The data were confirmed with the literature. The determination of the organic functional groups of the essential oil in natura was analyzed in the infrared spectrophotometer by Fourier transform and the larvicidal test was carried out in the Laboratory of Malaria and Dengue / LMDCSAS (INPA). The results showed that the essential oil of Piper callosum was stable and that safrole is its major constituent. Two typical stretches of double aromatic ring bonding were found in the FTIR for the components with the highest participation. Larvicidal activities were confirmed in large concentrations in the first $24 \mathrm{~h}$. The essential oil of Piper callosum is formed by several substances with diverse bioactive properties, being a promising alternative for the biological control of arboviruses.

Key-words: Aedes aegypti. Arboviruses. Biological control. Piper callosum.

\section{INTRODUÇÃO}

As doenças transmitidas por insetos têm se mostrado presentes em vários países, no entanto as nações emergentes são os alvos mais frequentes devido a vários fatores, como a falta de políticas públicas voltadas para o controle biológico de arboviroses. A prevenção é o método mais eficaz para evitar damos a saúde humana. Entre os vários vetores transmissores de arboviroses, - A. aegypti tem sido o principal por ser responsável pela transmissão de diversas doenças, em especial, a dengue, febre amarela, Chikungunya e Zika (FORATTINI, 1995). O A. aegypti se adapta fácil ao meio urbano e sua proliferação é mais extensa em países tropicais e subtropicais devido a temperatura, além da umidade presentes nessas regiões. $\bigcirc$ desenvolvimento do inseto é composto por quatro estágios até sua fase adulta, como aponta a Figura 1.

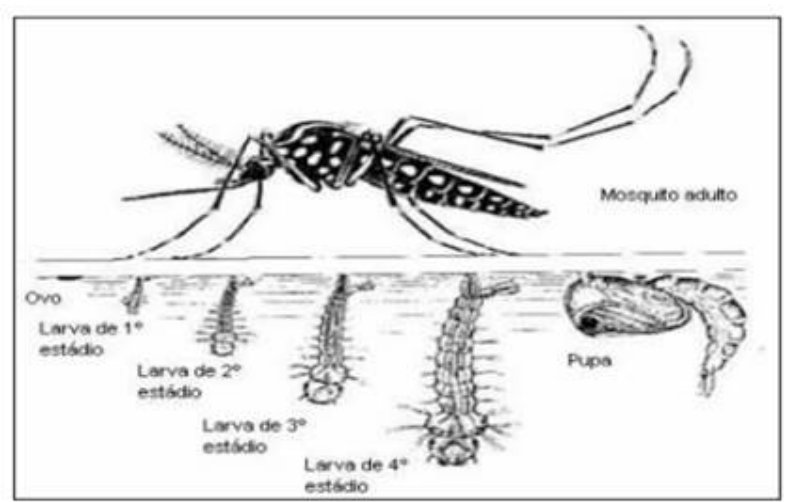

Figura 1 - Ciclo de vida do Aedes. Fonte: Consoli e Oliveira (1994).

Dentre as doenças transmitidas por insetos a dengue é a mais evidenciada e conhecida como a maior causadora de problemas de saúde pública e seus sintomas são diversos como febre, dor de cabeça, dores pelo corpo, náuseas ou até mesmo não apresentar qualquer sintoma. É uma infecção viral transmitida, principalmente, pelo mosquito $A$. aegypti, no Brasil e na Ásia, pelo A. albopictus. Essa doença é causada pelo vírus da família Flaviviridae, gênero Flavivirus.

Há quatro tipos sorologicamente distintos do Dengue vírus (DENV): DENV1, DENV-2, DENV-3 e DENV-4, que podem causar tanto a manifestação clássica da doença quanto à forma grave. Esses vírus são antagonicamente diferentes, não induzem proteção imunológica cruzada, porém, têm a mesma epidemiologia e causam doenças semelhantes em humanos. A região norte registra o maior índice de doenças transmitidas pelo mosquito da dengue por se uma região chuvosa na maior parte do ano (MINISTÉRIO DA SAÚDE, 2018). Além do Brasil, foi constatada a presença do $A$. aegypti em várias regiões do mundo (MAMANI, 2014).

Nos últimos anos os óleos essenciais, obtidos de plantas, têm sido considerados fortes fontes em potencial de substâncias biologicamente ativas. Esse amplo leque multifuncional por parte das plantas produtoras de óleos essenciais tem despertado grande interesse de pesquisadores em busca de inovações tecnológicas visando 
à redução dos agravos ocasionados pelo Aedes aegypti. A engenharia biomédica tem investido por meio da tecnologia em testes com óleos essenciais de várias espécies de plantas ricas atividades biológicas contra vários microrganismos patogênicos à saúde humana (ANDREANI et al., 2014).

Esses óleos essenciais possuem substâncias terpenóides que repelem os insetos e causam mortalidades em suas larvas. A constituição química dos óleos essenciais de determinadas plantas oscila de acordo com a sua espécie, e suas atividades biológicas estão relacionadas a seus constituintes e grupos funcionais (MIRANDA et al., 2016). Por essa razão, algumas delas podem apresentar funções específicas inseticidas, larvicidas, fungicidas, acaricidas, bactericidas etc. Tais funções vêm sendo exploradas por meio da engenharia biomédica e bioengenharia para o desenvolvimento de novas formulações biocidas e médicas.

Os óleos essenciais são extraídos de folhas, caules, sementes e flores de várias espécies da flora brasileira em especial da amazônica, porém sua utilização para tecnologia na região norte ainda não é satisfatória comparada a outras regiões do Brasil, apesar de que as maiores concentrações das espécies ricas em óleos essenciais encontram- se no Norte do país. A quantidade de óleo essencial extraído da espécie Piper é abundante, além das múltiplas funções biológicas e diversas aplicações, inclusive na medicina tradicional (SILVA; BASTOS, 2007). A Amazônia possui um dos maiores ecossistemas mundiais com uma ampla variedade de plantas ricas em óleos essenciais com funções bioativas e medicinais (ANDRADE; GUIMARÃES; MAIA, 2009; TAKEARA, 2017).

As plantas que fazem parte do grupo Piperaceae, além de serem grandes produtoras de óleos, são ricas em substâncias bioativas. Dentre essas espécies destacam-se a Piper nigrum, Piper aduncum, Piper hispidinervum e Piper marginatum, as quais possuem atividades inseticidas e larvicidas comprovadas (COSTA etal., 2010; SILVA et al.,
2018). Os óleos essenciais de determinadas espécies vegetais possuem inúmeras atividades biocidas (SOUTO; HARADA; MAIA, 2011; SILVA; BASTOS, 2007). Essas espécies são vistas respectivamente na Figura 2.
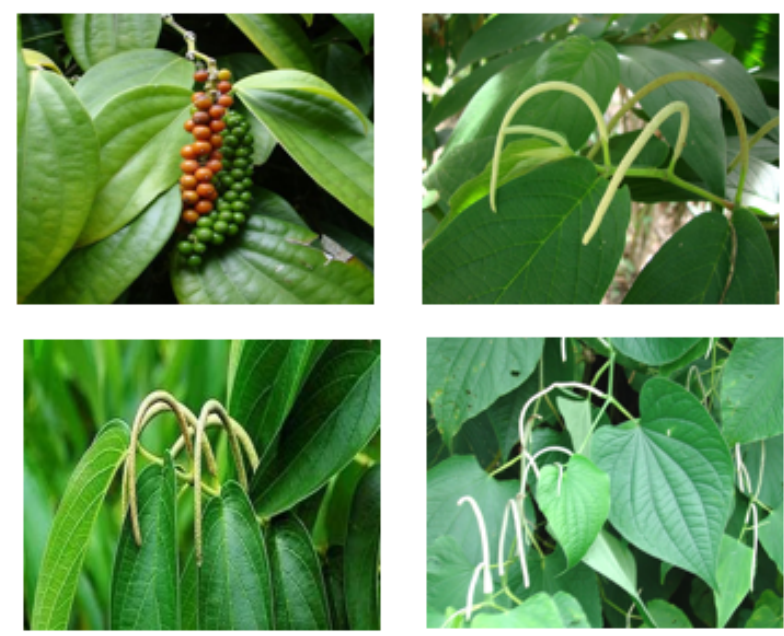

Figura 2 - Respectivamente a Piper nigrum, Piper aduncum, Piper hispidinervum e Piper marginatum.

Fonte: Autoria própria (2019).

A Piper callosum é o maior gênero da família Piperaceae (REGINFO-SALGADO; FERNANDEZ-VILCHEZ; VARGAS-ARANA, 2010) e encontra-se amplamente distribuída no norte do país. Essa espécie é subarbustiva perene, com caules subarbusto e ramos nodosos, folhas alternas com as nervuras permanentes na face central, flores pequenas, amareladas e agregadas em espigas volumosas conforme Figura 3. Além disso, apresenta uma predisposição por climas quentes e solos ricos em matéria orgânica, justificando o fato de ser amplamente encontrada no Estado do Amazonas.

No Amazonas a Piper callosum é conhecida popularmente como óleo elétrico, esta espécie é constituída por terpenóides, monoterpenos e fenilpropanóides (ação defensiva). Ultimamente torna-se grande a procura por esta espécie por se tratar de uma planta com múltiplas funcionalidades. Estudos comprovam a utilização de constituintes do óleo essencial de Piper callosum no combate a doenças, pragas e bactérias (SILVA; BASTOS, 2007). O povo nortista faz 
uso da Piper callosum para matar insetos e regular as funções do estômago, pois é uma planta com vastas funções terapêuticas e com grande ascensão para aplicação nas atividades biomédicas.

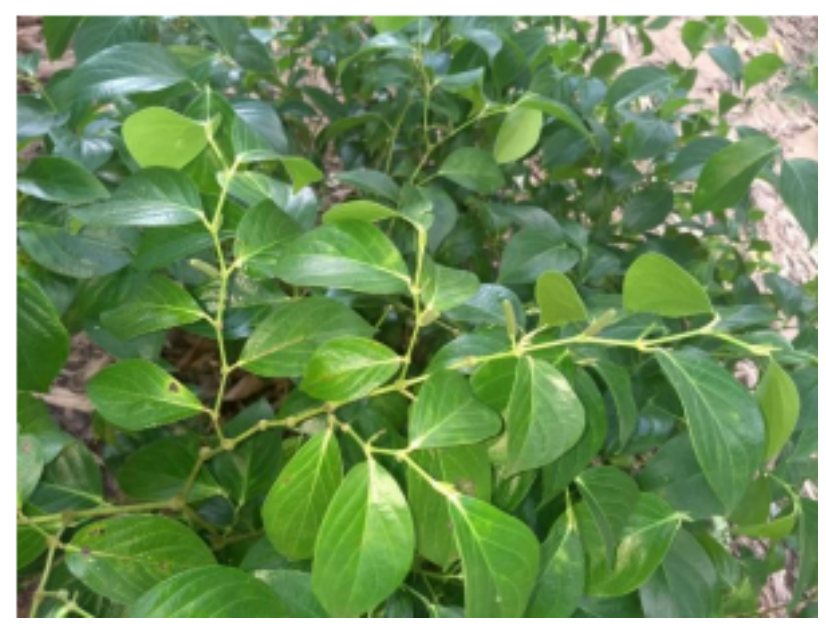

Figura 3 - Piper callosum.

Fonte: Autoria própria (2019).

Baseado nos relatos científicos referentes ao uso de óleos essenciais para o controle biológico de organismos (insetos), o objetivo desta pesquisa versou em confirmar por meio de ensaios larvicidas a eficácia do óleo essencial da Piper callosum contra larvas do mosquito Aedes aegypti.

\section{MATERIAIS E MÉTODOS}

Trata-se de um estudo experimental simulado, na qual foram cedidos $100 \mathrm{~mL}$ do óleo essencial da Piper callosum pela Empresa Brasileira de Pesquisa Agropecuária (Embrapa), situada na Rodovia AM-010 de Manaus-Itacoatiara, no Km 30, o índice de refração do óleo essencial foi analisado no refratômetro ATAGO, MASTER REFRACTOMETER (NANOPOL - UFAM).

A constituição química do material fornecido foi determinada por Cromatografia Gasosa acoplada à Espectrometria de Massas (CG/EM) na Central Analítica/UFAM, no equipamento Thermo, modelo Trace GC Ultra, coluna capilar Tr-5 (30 m x 0,25 mm x $0,25 \mu \mathrm{m})$ utilizando He como gás de arraste
(1.0 mL. $\left.\mathrm{min}^{-1}\right)$. O volume injetado foi de 2 $\mu \mathrm{L}$ do óleo essencial in natura diluído em $1 \mathrm{~mL}$ de acetato de etila. A temperatura foi de $250{ }^{\circ} \mathrm{C}$ no injetor e a temperatura do forno foi programada em $40{ }^{\circ} \mathrm{C}$ (4 min), aumentando até $240{ }^{\circ} \mathrm{C}$, com acréscimo de $4{ }^{\circ} \mathrm{C} \cdot \mathrm{min}^{-1} \mathrm{e}$, em seguida, aumentando até $280^{\circ} \mathrm{C}$ a uma taxa de $10^{\circ} \mathrm{C}$ durante $2 \mathrm{~min}$. Os dados foram confirmados com a literatura (ADAMS, 2007).

A determinação dos grupos funcionais orgânicos do óleo essencial in natura foi analisada no Espectrofotômetro de Infravermelho por transformada de Fourier da marca Shimadzu, modelo IR Prestige-21, utilizando-se o software IR solution versão 1.6, modo transmitância, 64 scans, no intervalo de 4000 a $500 \mathrm{~cm}^{1}$. As medias foram realizadas no Hub Tecnologia e Inovação (Manaus/AM).

O teste larvicida foi realizado no Laboratório de Malária e Dengue/LMD-CSAS (INPA) para testar o óleo essencial in natura da Piper callosum grupos de 10 larvas no $3^{\circ}$ estágio larval foram colocados em copos plásticos (100 mL) contendo inicialmente $1 \mathrm{~mL}$ de água destilada e $100 \mu \mathrm{L}$ do alimento larval e $100 \mu \mathrm{L}$ das concentrações larvicidas (72 a $\left.48 \mathrm{mg} \cdot \mathrm{mL}^{-1}\right)$, (47 a $35 \mathrm{mg} \cdot \mathrm{mL}^{-1}$ ) do óleo essencial solubilizado em DMSO. As leituras foram realizadas após 24 e 48 h de exposição, logo sendo consideradas mortas as larvas que não responderam a estímulos artificiais.

\section{RESULTADOS E DISCUSSÃO}

\section{Índice de refração do óleo essencial}

O índice de refração foi utilizado para verificar o estado físico-químico do óleo essencial (OE). $\bigcirc$ valor do índice de refração (IR) foi de 1,52, corroborando Calderari (2002) com 1,52. A Figura 4 aponta o valor do IR. Esses dados confirmam que o óleo essencial da Piper callosum mostrou suas propriedades físicas e químicas estáveis, sem oxidação e fotodegradação com base 
na Farmacopeia Brasileira (ANVISA, 2010). Esse resultado provou que O OE da Piper callosum tem características estáveis e pode ser usado como um ativo natural.

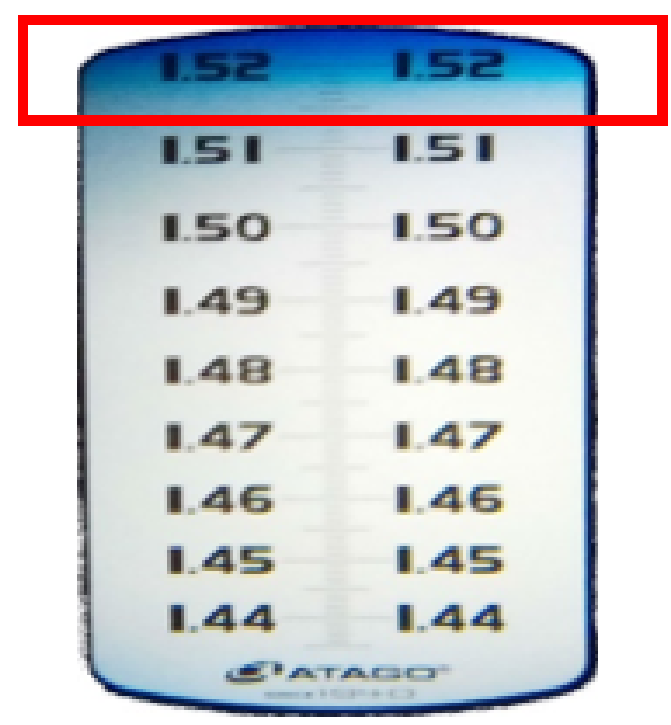

Figura 4 - Índice de refração do óleo essencial da Piper callosum

Fonte: Autoria própria (2019).

\section{Cromatografia gasosa acoplada} ao espectrômetro de massa CG/EM

A técnica de CG/EM permitiu a identificação de 8 monoterpenos que compõem $20 \%$ do OE; 3 fenilpropenos que correspondem a $73 \%, 3$ sesquiterpenos com $1 \%$ e outros não identificados que somam 3,8 \%. No entanto, o principal componente do óleo essencial da Piper callosum foi o safrol (64 $\%)$, seguido pelo metileugenol (7,94\%), $\alpha$-pineno $(7,12 \%)$ e $\beta$-pineno $(6,62 \%)$ conforme Tabela 1. Esses dados são confirmados pelo cromatograma do óleo essencial da Piper callosum visto na Figura 5. Os constituintes com as maiores concentrações são citados na literatura por suas múltiplas ações biológicas (NEGREIROS; MIQUELONI; ALVARES, 2017; IC et al., 2003; SALEHI 2019; CHAVES et al., 2012) e são exibidos na Figura 6.

Tabela 1 - Constituintes químicos do óleo essencial da Piper callosum e em destaque os componentes majoritários.

\begin{tabular}{|c|c|c|c|}
\hline $\mathbf{N}^{\circ}$ & ÁREA & IRL & IRC \\
\hline $1 \alpha$-pineno & 7,12 & 932 & 931 \\
\hline 2 canfeno & 0,46 & 944 & 944 \\
\hline $3 \beta$-pineno & 6,62 & 974 & 972 \\
\hline 4 mirceno & 0,34 & 988 & 990 \\
\hline $5 \alpha$-terpineno & 1,42 & 1014 & 1013 \\
\hline 61,8 cineol & 3,68 & 1026 & 1027 \\
\hline $7 y$-terpineno & 2,83 & 1054 & 1057 \\
\hline 8 terpinoleno & 0,58 & 1086 & 1087 \\
\hline 9 camfor & 0,1 & 1141 & 1140 \\
\hline 10 terpine-4-ol & 0,52 & 1174 & 1176 \\
\hline 11 safrol & 63,7 & 1285 & 1290 \\
\hline 12 metil eugenol & 7,94 & 1403 & 1406 \\
\hline $13 y$-muuroleno & 0,24 & 1478 & 1478 \\
\hline 14 germacreno & 0,37 & 1480 & 1482 \\
\hline $15 \delta$-cardineno & 0,35 & 1522 & 1525 \\
\hline 16 elemicin & 0,88 & 1555 & 1559 \\
\hline Total identificado & 97,17 & & \\
\hline Monoterpenos & 19,89 & & \\
\hline \multicolumn{4}{|l|}{$n^{\circ} 1,2,3,4,5,7,8$ e 10} \\
\hline Fenilpropenos & 72,5 & & \\
\hline \multicolumn{4}{|l|}{$n^{\circ} 11,12$ e 16} \\
\hline Sesquiterpenos & 0,96 & & \\
\hline \multicolumn{4}{|l|}{$n^{\circ} 13,14$ e 15} \\
\hline Outros & 3,78 & & \\
\hline$n^{\circ} 6$ e 9 & & & \\
\hline
\end{tabular}

Fonte: Autoria própria (2019). 


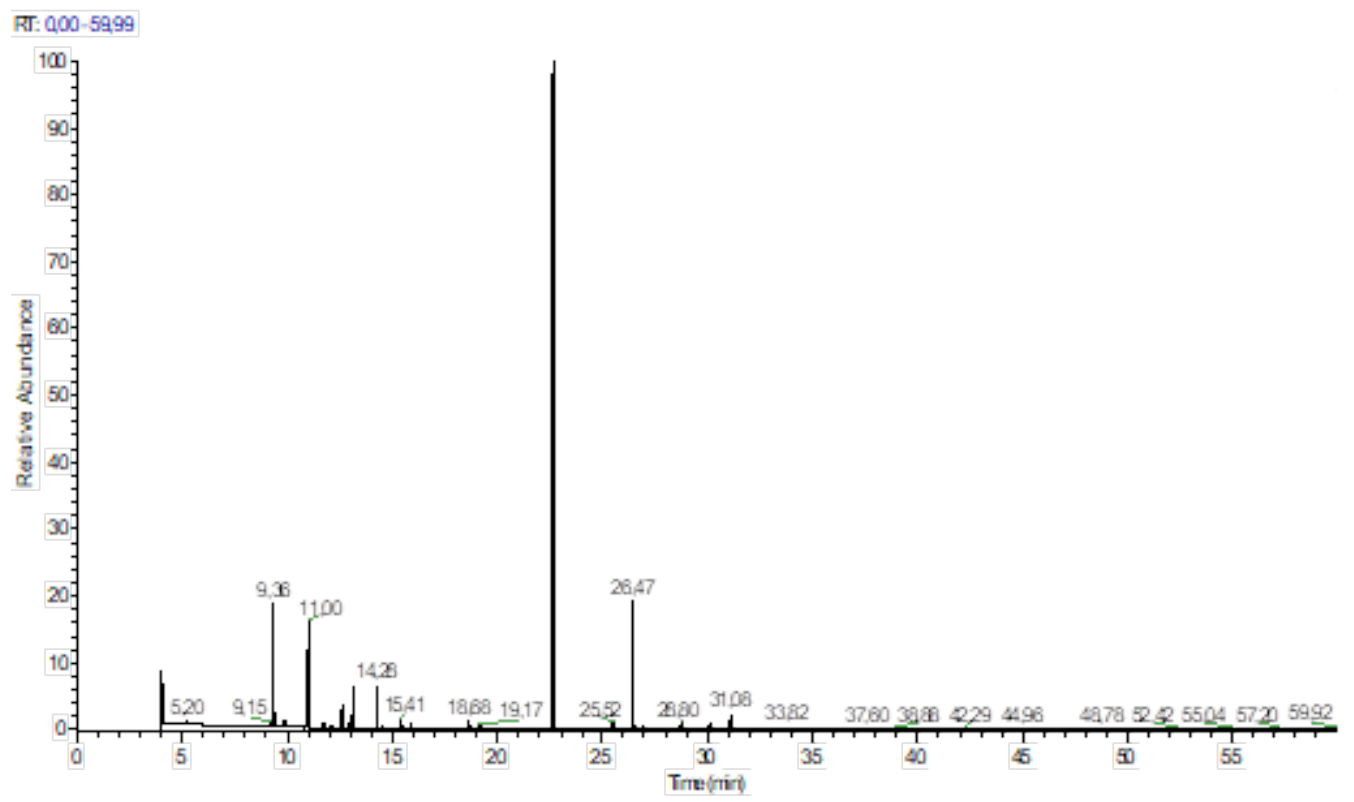

Figura 5 - Cromatograma do óleo essencial da Piper callosum.

Fonte: Autoria própria (2019).

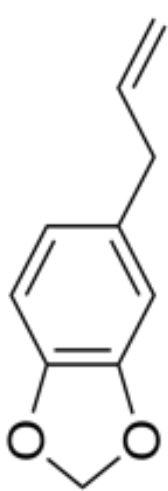

Safrol

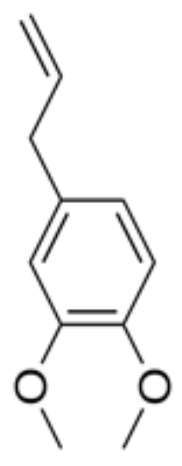

Metileugenol

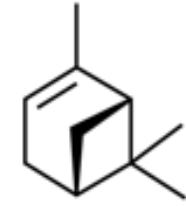

$\alpha$-pineno<smiles>C=C1CCC[C@@H]1C(C)(C)C</smiles>

$\beta$-pineno
Figura 6 - Constituintes majoritários do óleo essencial da Piper callosum.

Fonte: Autoria própria (2019).

Espectroscopia no infravermelho por transformada de Fourier (FTIR)

As bandas identificadas entre 3080-2720 $\mathrm{cm}^{-1}$ são $\mathrm{C}-\mathrm{H}$ de alcenos, provavelmente, um grupo de monoterpenos ( $\alpha$-pineno, $\beta$-pineno, limoneno e 1,8-cineol), como também vibrações de alcenos nas bandas entre 1180-800 $\mathrm{cm}^{-1}$ (LIMA; XAVIER; TEIXEIRA, 2017). Dois estiramentos típicos de ligação dupla de anel aromático em $1485 \mathrm{~cm}^{-1}$ e $1444 \mathrm{~cm}^{-1}$ também foram observados, e estão associados aos dois componentes com maiores participações no óleo essencial da P. callosum (safrol, metileugenol). Esses resultados confirmam o alto teor de substâncias biologicamente ativas presentes no óleo essencial mostrados no espectrograma na Figura 7.

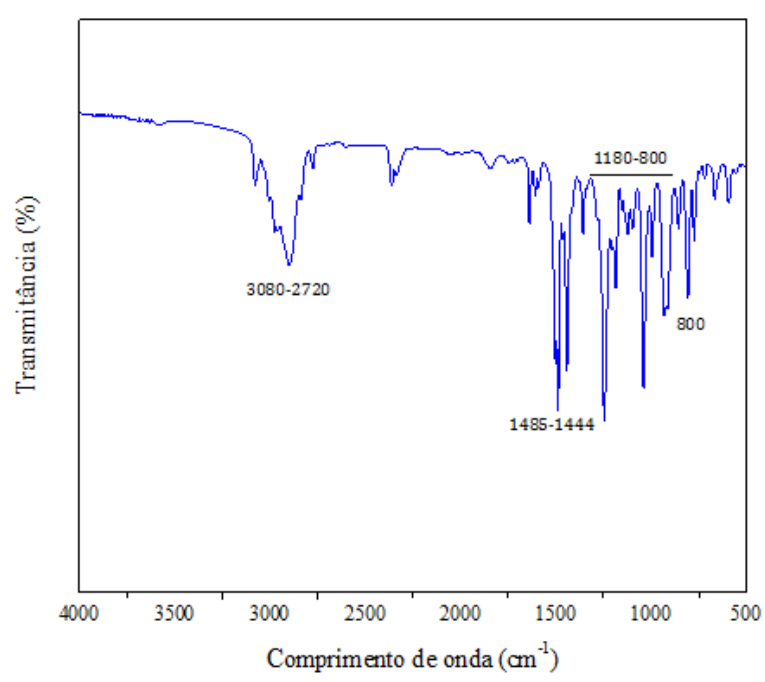

Figura 7 - Espectrograma do óleo essencial da Piper callosum.

Fonte: Autoria própria (2019). 
Os testes realizados com o óleo essencial da percentuais de mortalidade após esse intervalo de tempo conforme Tabela 2. Piper callosum demonstraram maior atividade

Tabela 2 - Valores de CL50 (concentração inibitória) e CL90 (concentração letal) do óleo essencial da Piper callosum in natura contra larvas Aedes aegypti.

\begin{tabular}{|c|c|c|c|c|c|}
\hline Espécie & Tempo (h) & $\begin{array}{c}\mathrm{CL}_{50} \pm \mathrm{DP} \\
\left(\boldsymbol{\mu g} \cdot \mathbf{m L}^{-1}\right)\end{array}$ & (LCI-LCS) & $\begin{array}{c}\mathrm{CL}_{90} \pm \mathrm{DP} \\
\left(\boldsymbol{\mu g} \cdot \mathbf{m L}^{-1}\right)\end{array}$ & (LCl-LCS) \\
\hline $\begin{array}{c}\text { Aedes } \\
\text { aegypti }\end{array}$ & 24 & $53.46 \pm 1$ & $52.12-57.91$ & $94.15 \pm 1$ & $87.44-124$ \\
\hline & 48 & $38.13 \pm 1$ & $37.49-40.02$ & $55.96 \pm 1$ & $53.33-67.23$ \\
\hline
\end{tabular}

Limite de confiança superior (LCS), limite de confiança inferior (LCI) e desvio padrão (DP).

Fonte: Autoria própria (2019).

Por meio das doses aplicadas foram encontrados os valores das concentrações letais $\mathrm{CL}_{50}$ e $\mathrm{CL}_{90}$ através da análise pelo programa POLOPC $\otimes$ (LeOra Software Berkeley, CA), respeitando o intervalo de confiança no nível de significância de 95\%. O estudo de toxicidade larval apontou que o óleo essencial apresenta maior atividade larvicida nas primeiras 24 horas. As concentrações letais consideráveis foram $(53.46 \pm 1)$ e $(94.15 \pm 1)$ rg. $\mathrm{mL}^{-1}$ para $\mathrm{CL}_{50}$ e $\mathrm{CL90}$, respectivamente. No entanto as atividades registradas em 48 $\mathrm{h}$ foram essenciais para complementar e comprovar a eficácia do óleo essencial da Piper callosum contra as larvas do mosquito da dengue (Aedes aegypti). Normalmente, nas primeiras horas de ensaios biológicos os organismos alvos apresentam maior mortalidade, nas horas seguintes os efeitos são menores, porém mais extensos (ROEL, 2001).

O óleo da Piper callosum apresentou atividade larvicida a partir da concentração de 48 ppm nas primeiras $24 \mathrm{~h}$. No entanto, a mortalidade das larvas foi representativa somente a partir da concentração de 72 ppm. Os percentuais de mortalidade foram bastante distintos entre as concentrações utilizadas, nas primeiras $24 \mathrm{~h}$ do experimento, sendo verificado aumento gradual no percentual de mortalidade à medida em que a concentração foi aumentada.
O constituinte majoritário do óleo essencial da Piper callosum (safrol) apresenta atividades larvicidas contra o Aedes aegypti comprovadas cientificamente (SIMAS et al., 2004; SANTOS, 2014), como também o ? pineno (GOMES et al., 2016).

\section{CONSIDERAÇÕES FINAIS}

O presente trabalho testou com sucesso o óleo essencial da Piper callosum em larvas do mosquito Aedes aegypti. O óleo essencial se mostrou estável quando analisado no refratômetro.

A espectroscopia no infravermelho identificou os componentes majoritários e os grupos funcionais da Piper callosum e o ensaio biológico apresentou atividade larvicida a partir da concentração de 48 ppm nas primeiras $24 \mathrm{~h}$. No entanto, a mortalidade das larvas foi representativa somente a partir da concentração de 72 ppm.

Os percentuais de mortalidade foram bastante distintos entre as concentrações utilizadas, nas primeiras $24 \mathrm{~h}$ do experimento, sendo verificado aumento gradual no percentual de mortalidade à medida em que a concentração foi aumentada. 
Os resultados desta pesquisa comprovaram que o óleo essencial da Piper callosum possui atividade biocida contra a larva do mosquito Aedes aegypti e que é um bioativo natural promissor para o desenvolvimento de formulações alternativas para o controle de vetores que causam danos à saúde humana e as suas funções biológicas estão ligadas aos seus componentes majoritários. 


\section{REFERÊNCIAS}

ADAMS, R. P. Identification of Essential Oil Components by Gas Chromatography/Mass Spectrometry. [S.I.]: Allured Publishing Corporation, 2007.

AGÊNCIA NACIONAL DE VIGILÂNCIA SANITÁRIA - ANVISA.

Farmacopeia Brasileira. 5. ed. Brasília: Fundação Oswaldo Cruz, 2010.

ANDREANI, G. et al. Avaliação do efeito fungicida da água ozonizada e de plantas medicinais sobre Candida albicans. In: CONGRESSO BRASILEIRO DE ENGENHARIA BIOMÉDICA - CBEB, 24., 2014, Fernandópolis-SP. Anais [...]. Fernandópolis-SP: Instituto de Engenharia Biomédica, 2014.

ANDRADE, E. H. A.; GUIMARÃES, E. F.; MAIA, J. G. S. Variabilidade química em óleos essenciais de espécies de Piper da Amazônia. Belém: FEQ; UFPA, 2009. 448p.

CALDERARI, M. T. Estudos de óleos essenciais de Piperaceae do Vale do Itajaí. 2002. 117 f. Dissertação (Mestrado em Química) Universidade Federal de Santa Catarina, Florianópolis, 2002.

CHAVES, F. C. M. et. al. Variação da composição química do óleo essencial de Piper callosum Ruiz \& Pav. em função de níveis de luminosidade. In: INTERNATIONAL SYMPOSIUM ON MEDICINAL AND NUTRACEUTICAL PLANTS, 3., 2012, Aracajú. Anais [...]. Aracajú, 2012.

CONSOLI, R.; OLIVEIRA, R. L. Principais mosquitos de importância sanitária no Brasil. Rio de Janeiro: Editora FIOCRUZ, 1994. 228 p. E-book.

COSTA, J. G. M. et al. Composição Química e toxicidade de óleos essenciais de espécies de Piper Frente a Larvas de Aedes aegypti L. (Diptera: Culicidae). Latin American Journal of Pharmacy, v. 29, n. 3, p. 463-7, 2010.

FORATTINI, O. P. Principais mosquitos de importância sanitária no Brasil. Cadernos de Saúde Pública, v. 11, n. 1, p. 157-158, 1995.

GOMES, P. R. B. et al. Avaliação da atividade larvicida do óleo essencial do Zingiber officinale Roscoe (gengibre) frente ao mosquito Aedes aegypti. Revista brasileira de plantas medicinais, Botucatu, v. 18, n. 2, 2016. Supl.1. 
IC, Y. O. L. et al. Constituintes químicos e atividade inseticida do óleo essencial de Piper callosum. Anais da Sociedade Brasileira de Química, v. 10, n. 3, p. 1997, 2003.

LIMA, I. K. C.; XAVIER, M. R.; TEIXEIRA, A. M. R. Análise das bandas vibracionais do óleo essencial de Eucalyptus globulos e de seus constituintes majoritários obtidas por métodos teóricos e experimental.

Reunião Regional da SBPC no Cariri (URCA), Crato, 2017.

MAMANI, E. Nuevo serotipo 5 del virus dengue: necesidad de fortalecer la vigilancia molecular en Perú. Revista peruana de medicina experimental y salud pública, v. 31, n. 1, p. 169-180, 2014.

MINISTÉRIO DA SAÚDE. Secretaria de Vigilância em Saúde. Monitoramento dos casos de dengue, febre de Chikungunya e doença aguda pelo vírus Zika até a Semana Epidemiológica de 2018. Boletim Epidemiológico, v. 49, n. 44, p. 1-14, nov. 2018.

MIRANDA, C. A. S. F. et al. óleos essenciais de folhas de diversas espécies: Propriedades antioxidantes e antibacterianas no crescimento espécies patogênicas. Revista Ciência Agronômica, v. 47, n. 1, p. 213-220, 2016.

NEGREIROS, J. R. S.; MIQUELONI, D. P.; ALVARES, V. de S.

Comportamento do composto majoritário de óleos essenciais de espécies de Piper da Amazônia sob armazenamento.

Acre: Embrapa, 2017.

REGINFO-SALGADO, E. L.; FERNANDEZ-VILCHEZ, C. M.; VARGASARANA, G. Búsqueda y evaluación de aceites esenciales em espécies amazônicas. Folia Amazónica, v. 20, n. 2-1, p. 29-32, 2010.

ROEL, A. R. Utilização de plantas com propriedades inseticidas: uma contribuição para o desenvolvimento rural sustentável. Revista Internacional de Desenvolvimento Local, v. 1, n. 2, p. 43-50, 2001.

SALEHI, B. et al. Piper Species: A Comprehensive Review on Their Phytochemistry Biological Activities and Applications. Molecules, v. 24, n. 7, p. 1-118, 2019.

SANTOS, S. R. L. Síntese de compostos potencialmente larvicidas frente ao Aedes aegypti. 2014. Dissertação (Mestrado em Ciências Farmacêuticas) - Universidade Federal de Sergipe, Aracajú, 2014.

SILVA, D. M. M. H.; BASTOS, C. N. Antifungal activity of Essential Oils of Piper Species About Crinipellis perniciosa, Phytophthora palmivora e Phytophthora capsici. Fitopatol. Bras., v. 32, n. 2, p. 143-145, 2007. 
SILVA, L. S. et al. Encapsulation of Piper aduncum and Piper hispidinervum essential oils in gelatin nanoparticles: a possible sustainable control tool of Aedes aegypti, Tetranychus urticae and Cerataphis lataniae. Journal of the Science of Food and Agriculture, v. 99, n.2, p. 685-695, jun., 2019.

SIMAS, N. K. et al. Produtos naturais para o controle da transmissão da dengue - atividade larvicida de Myroxylon balsamum (óleo vermelho) e de terpenóides e fenilpropanóides. Química Nova, v. 27 , n. 1, p. 46-49, 2004.

SOUTO, R. N. P.; HARADA, A. Y.; MAIA, J. G. S. Estudos preliminares da atividade inseticida de óleos essenciais de espécies de Piper linneus (piperaceae) em operárias de Solenopis saevissima f Smith (Hymenoptera: formicidae), em laboratório. Biota Amazônia, Macapá, v. 1, n. 1, p. 42-48, 2011.

TAKEARA, R. et al. Biological Properties of Essential Oils from the Piper Species of Brazil: A Review. In: EL-SHEMY, H. A. Aromatic and Medicinal Plants: Back to Nature. [S.I.]: Intech Open, 2017. p. 82-93. 